reabilitação oral da região do QO deve respeitar um período de regeneração óssea, ser classicamente autóloga. constituindo a utilização de implantes dentários ainda uma controvérsia. Este trabalho objetiva apresentar um caso clínico de um QO mandibular, com excisão cirúrgica, acompanhamento clínico e reabilitação fixa implantar subsequente, alertando a comunidade de profissionais de saúde oral da utilidade da avaliação da expressão génica celular óssea no timing da reabilitação oral.

Descrição do caso clínico: Paciente do sexo feminino, caucasiana, 31 anos, procurou o médico dentista para extração dos terceiros molares. A radiografia panorâmica evidenciou imagem radiolúcida no ramo mandibular esquerdo. Clinicamente não se observou sinal ou sintoma coincidente com o achado imagiológico. O diagnóstico clínico foi de QO associado ao dente 3.8. Procedeu-se à excisão cirúrgica do QO e exodontia do 3.8, seguida da análise histopatológica da lesão, que confirmou o diagnóstico. Durante o procedimento cirúrgico, verificou-se que a lesão envolvia a raiz do 3.7, conduzindo à sua perda. Após 6 anos de controlo clínico e radiográfico, sem qualquer recidiva, foi realizada uma reabilitação oral fixa no local do 3.7 com a colocação de um implante dentário e respetiva coroa fixa, permanecendo até à data estável (10 anos).

Discussão e conclusões: O QO é geralmente identificado, por rotina, como um achado radiográfico. Embora benigno, requer intervenção cirúrgica, idealmente através da enucleação do cisto, seguida de curetagem. O acompanhamento do paciente com diagnóstico precoce de QO deve ser anual, até à idade de 18 anos, para poderem ser reabilitados com implantes dentários e eventual recurso a aloenxertos. Nesta fase, a avaliação da expressão génica das células ósseas pode constituir uma mais-valia para o clínico, na decisão do tipo e inicio da reabilitação oral e efetuar.

http://doi.org/10.24873/j.rpemd.2018.11.253

\section{\#013 Síndrome Apneia obstrutiva do sono e cirurgia ortognática - a propósito de um caso clínico}

Maria Inês Mendonça Ribeiro Tavares**, Inês Fonseca, Susana Silva, Rita Carvalho, João Pedro Marcelino, Miguel M. Gonçalves

Universidade Católica Portuguesa - Viseu

Introdução: A síndrome da apneia obstrutiva do sono (SAOS) corresponde a um colapso e consequente obstrução da via aérea superior durante o sono, o que leva a períodos de apneia/hipopneia e a uma diminuição da saturação de oxiemoglobina. A perda do padrão normal do sono manifesta-se desde a roncopatia à hipoventilaçao nocturna profunda. Os Médicos Dentistas têm um papel importante no rastreio da SAOS e devem fazer o correcto encaminhamento para o centro do sono, devendo estar atentos às seguintes características: retrognatia (classe II); palato profundo; arcos dentários estreitos; edentações da língua; macroglossia; aumento do tamanho das adenóides e amígdalas; alterações do tamanho da orofaringe; bruxismo; retracção gengival e perdas dentárias. As opções de tratamento são a administração, por via nasal, de uma pressão positiva de ar (CPAP), o uso de dispositivos para avanço mandibular e/ou o tratamento cirúrgico que compreende as seguintes técnicas: uvulopalatofaringoplastia e/ou avanço maxilo-mandibular.

Descrição do caso clínico: Género masculino, 49 anos, raça caucasiana, braquifacial, classe III esquelética, diagnóstico de SAOS, utiliza CPAP durante a noite. Recorreu a consulta de ortodontia em contexto de clínica privada, tendo sido aconselhada tratamento ortodôntico fixo durante 12 meses (pré-operatório) para correção do arco dentário e posterior intervenção cirúrgica de avanço maxilo-mandibular. O tratamento ortodôntico teve duração de 20 meses, sendo terminado em Janeiro de 2018. Foi realizada cirurgia ortognática em Outubro de 2017, com avanço de $4 \mathrm{~mm}$ mandibulares e $2 \mathrm{~mm}$ maxilares, tendo o tratamento foi dado como terminado em Março de 2018.

Discussão e conclusões: A cirurgia de avanço maxilo-mandibular (AMM) compreende uma osteotomia de Le Fort tipo 1 maxilar e osteotomia sagital dos ramos mandibulares, que permitem o avanço maxilar e consequente aumento do espaço orofaríngeo e também correção do arco dentário. Este avanço promove a expansão das vias aéreas, em vários planos, podendo ser constatado nas telerradiografias de perfil, na tomografia computadorizada e na ressonância magnética. Com esta intervenção dá-se um aumento da profundidade faríngea, aumento da saturação de $\mathrm{O} 2$ mínima no pós-operatório, menor sonolência, aumento da atividade social e vigília e, melhorias na estética facial. A cirurgia AMM é a opção cirúrgica mais bem-sucedida para o tratamento da SAOS de moderada a grave, com uma taxa de sucesso entre $75 \%$ e $100 \%$.

http://doi.org/10.24873/j.rpemd.2018.11.254

\#014 Reabilitações Orais Com Implantes

Zigomáticos - Todos Os Pacientes São Bons Candidatos?

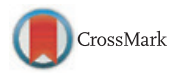

L Tovim*, MM Sampaio Fernandes, S Oliveira, MH Figueiral, JC Sampaio Fernandes, Paula Vaz

\section{FMDUP}

Introdução: O presente trabalho teve como objetivo apresentar um caso clínico de perda óssea generalizada nos maxilares e insucesso recorrente de implantes dentários convencionais, posteriormente reabilitado com prótese fixa maxilar e mandibular, através de quatro implantes zigomáticos e quatro implantes mandibulares, e chamar a atenção para o papel da suscetibilidade genética na presença de complicações biológicas com implantes zigomáticos.

Descrição do caso clínico: Paciente Caucasiana. do sexo feminino, de 68 anos, com perda da totalidade de uma reabilitação oral fixa no maxilar superior ( 5 implantes) e 8 peças mandibulares dentárias inviáveis, pretendia uma reabilitação fixa bimaxilar. Após uma detalhada anamnese, exame clínico e imagiologico, optou-se pela realização de reabilitação oral fixa bimaxilar provisória, com 4 implantes zigomáticos, com carga imediata e 4 implantes mandibulares, igualmente com carga imediata. Como a paciente revelou uma perda óssea severa com a reabilitação fixa implantar prévia, foi realizado um 
estudo de susceptibilidade genética para o desenvolvimento de complicações biológicas com implantes dentários. Este estudo genético (genes IL1, IL1RN e IRAK4) revelou um genótipo de baixo risco. Sendo que até à data ( 3 anos), a paciente mantem um bom estado geral ósseo nos maxilares e não revela sinais de inflamação bucal.

Discussão e conclusões: A realização de carga imediata com implantes zigomáticos é considerada uma alternativa viável na reabilitação fixa do maxilar superior atrófico. No entanto, a literatura sobre o sucesso da reabilitação oral com carga imediata de implantes zigomáticos é parca. Acrescendo-se que foram descritas algumas complicações biológicas, raras, em reabilitações com implantes zigomáticos, levantam-se questões importantes e dúvidas a serem esclarecidas.O estudo genético (genes IL1, IL1RN e IRAK4) poderá constituir uma ferramenta promissora na planificação de casos em que os implantes zigomáticos se colocam como uma opção de reabilitação oral. Estudos clínicos, com amostras elevadas, de pacientes reabilitados com implantes zigomáticos tornam-se emergentes.

http://doi.org/10.24873/j.rpemd.2018.11.255

\section{\#015 Gengivectomia com laser Er-YAG guiada por Digital Smile Design - Caso Clínico}

Alexandra Marques*, Isabel Lopes, Luis Monteiro

IUCS Cespu

Introdução: O sorriso é considerado um pilar essencial na estetica facial pois as expressões faciais mais relevantes do ser humano são realizadas através do sorriso. O resultado da exposição dos dentes e da gengiva durante a contração do grupo muscular do terço inferior e médio da face, resultam no que chamamos sorriso, e a sua harmonia não é só determinada pela cor, forma e posição dos dentes mas também pela percepção visual da quantidade de tecido gengival exposto. Quando a exposição é demasiada ou a coroa clinica é muito curta temos um sorriso inestetico. Actualmente mediante um planeamento com o Digital Smile Design- DSD podemos de forma previsivel aferir a quantidade de gengiva que tem de ser removida. O DSD é baseado na utilização de ferramentas digitais de alta definição, com a possibilidade de uma visão estática e dinâmica, promovendo um plano de tratamento reverso individualizado.

Decrição do caso clínico: O objectivo do presente caso clinico é apresentar uma gengivectomia realizada com laser Er-Yag cujo planeamento foi realizado mediante a utilização de uma ferramenta digital- DSD, seguida de uma biomodulação dos tecidos com laser Nd-Yag. Na primeira consulta foi realizado o protocolo fotográfico utilizado no DSD, e foi feita uma leitura com scanner intraoral. Mediante o planeamento do DSD foi realizada uma guia cirúrgica. Na segunda consulta a paciente realizou a gengivectomia com Laser ER-YAG e biomodulaçao com laser Nd Yag.

Discussão e conclusões: O laser de Er-YAG é actualmente o indicado pela FDA para a realização de procedimentos de osteotomia por emitir comprimento de onda muito absorvido pela água e hidroxiapatite e por ser pouco profundo. A gengi- vectomia com laser está associada a menor hemorragia; é um procedimento menos invasivo; necessita de menos quantidade de anestésico local; está associada a um maior conforto pós-operatório e há possibilidade de realização imediata de procedimentos restauradores; quando associado ao DSD traz resultados com elevada previsibilidade.

http://doi.org/10.24873/j.rpemd.2018.11.256

\section{\#016 Cirurgia Guiada de Implante - técnica simplificada}

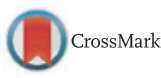

Eduardo Mendes de Paula*, Paulo Gustavo Cavalcanti Bandeira, Keuler Ferreira Rangel, Eder Ferreira Rangel, Asbel Rodrigues Machado

Diamond Clinic e Courses; Universidade Fernando Pessoa; Universidade Federal de Uberlândia - Brasil

Introdução: A Medicina Dentária moderna foi amplamente beneficiada com a disseminação dos princípios da osseointegração, de maneira que os implantes dentários, nos dias de hoje, tornaram-se a modalidade de escolha para a reabilitação de dentes ausentes. Entretanto, o sucesso do tratamento depende dentre vários fatores, de um bom planejamento e a uma cirurgia para instalação precisa e compatível com o planejado pré-operatoriamente. Neste sentido, o recurso de softwares interativos e o uso de guias cirúrgicas restritivas são excelentes auxílios para a execução das osteotomias e para a fixação dos implantes, objetivando maior previsibilidade e abordagem menos traumática.

Descrição do caso clínico: O objetivo deste trabalho é ilustrar o caso clínico do paciente LM, 80 anos, no qual foi realizada reabilitação total inferior com implantes dentários, através da técnica de cirurgia guiada simplificada, chamada de KEATech, que utilizou a própria prótese total inferior do paciente como guia tomográfica, guia cirúrgica e a mesma foi convertida, imediatamente após a colocação dos implantes, na prótese híbrida provisória.

Discussão e conclusões: Como todo o processo foi realizado completamente no próprio consultório dentário, com o auxílio do software e de um dispositivo posicionador de tubos (DPT), conclui-se, após o trabalho executado, que a efetividade e simplicidade de tal técnica, podem contribuir para melhores resultados, com redução de tempo e custo operacional. http://doi.org/10.24873/j.rpemd.2018.11.257

\section{\#017 Pênfigo Vulgar - Da Literatura Para A Clínica}

Rafaela Vaz*, Inês Vaz Silva, Cristina Moreira, Lia Jorge, Maria Teresa Corrales Hernández, Sónia Viegas

\section{CHVNG-E}

Introdução: O pênfigo pertence a um grupo de doenças auto-imunes que se carateriza pela formação de lesões bolhosas, com afecção muco-cutânea, devido à presença de auto-anticorpos contra os queratinócitos, resultando na perda da adesão intercelular através de um processo designado acantólise. Estima-se que a incidência seja de um a cinco casos por 